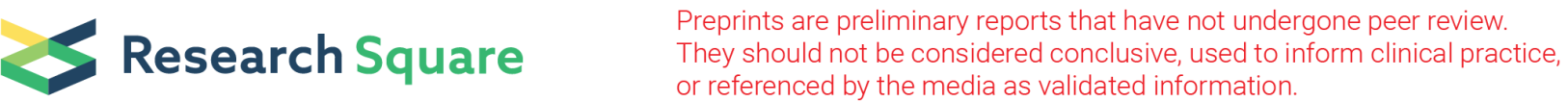

\section{Folic Acid Conjugated PEG-PCL-PEG Triblock Copolymer Nanoparticles for Enhanced Delivery of 5-Fluorouracil to HT29 Colon Cancer Cells}

\section{Parvin Sadat Mirzaghavami}

Iran University of Medical Sciences

Samideh Khoei ( $\boldsymbol{\nabla}$ khoei.s@iums.ac.ir)

Finetech in medicine research center, Iran University of Medical Sciences, Tehran, IRAN 3- Department of

Medical Physics, School of Medicine, Iran University of Medical Sciences, Tehran, IRAN https://orcid.org/0000-0001-9357-0229

\section{Sepideh Khoee}

University of Tehran

\section{Sakine Shirvalilou}

Iran University of Medical Sciences

\section{Research}

Keywords: triblock copolymer, magnetite nanoparticles, folic acid, colon cancer, 5-Fluorouracil

Posted Date: August 20th, 2020

DOl: https://doi.org/10.21203/rs.3.rs-58920/v1

License: (1) This work is licensed under a Creative Commons Attribution 4.0 International License. Read Full License 


\section{Abstract}

Background: In the current study, folic acid conjugated magnetite PEG-PCL-PEG triblock copolymer were synthesized and loaded with 5-Fluorouracil (5-FU-SPION-PEG-PCL-PEG-FA) for targeted delivery of drug to HT29 colon cancer cells.

Methods: The cytotoxic effect and cellular uptake of synthesized nanoparticles was assessed on HUVEC and HT29 cell lines. In addition, antitumor effects of nanoparticles were investigated based on gene expression of $\mathrm{Bax}$ and $\mathrm{Bcl} 2$, Annexin V/PI staining, ROS production and colony formation.

Results: As compared to 5-FU, an improvement in therapeutic index was demonstrated for 5-FU-SPIONPEG-PCL-PEG-FA according to cytotoxicity induced in HUVEC and HT29 cells. In addition, 5-FU-SPIONPEG-PCL-PEG-FA was found to be more antitumor efficient in comparison to 5-FU based on Bax/Bcl2 ratio, percentage of cell death, ROS production and colony formation ability $(P<0.05)$.

Conclusion: The obtained results suggested that 5-FU-SPION-PEG-PCL-PEG-FA could be considered as promising targeted drug delivery system.

\section{Background}

Colorectal cancer is among three most prevalent cancers in both men and women with high rate of mortality [1]. 5-Fluorouracil (5-FU) is currently known as the first-line chemotherapeutic drug for treatment of colorectal cancer which interfere with DNA and RNA synthesis through inhibition of thymidylate synthesis. However severe side effects and a low response rate, approximately $15 \%$, have been reported for this drug. The main reasons for its low efficiency includes: short half-life in plasma due to catabolization into inactive metabolites by dihydropyrimidine dehydrogenase (DPD), wide systemic body distribution and development of multidrug resistance [2]. Developing nanotechnology-based drug delivery system has been suggested owing to its ability to encapsulate and release drug in a controlled manner in specific sites. Amphiphilic copolymers which consist of hydrophobic and hydrophilic parts are referred to as an efficient drug delivery system because of their ability to assemble into a micellar form with a hydrophobic core for encapsulating drug and a hydrophilic shell for increasing blood circulation time [3, 4]. Poly- $\varepsilon$ - caprolactone (PCL) is a hydrophobic polyester approved by FDA.hydrolysis of PCL through esterase cleavage cause it to be completely converted to 6-hydroxycaproic acid, which is considered as natural metabolite in the body $[5,6]$. This hydrolytic degradation is a very slow process due to its high hydrophobicity and crystallinity nature. PCL copolymerization using hydrophilic polymers like polyethylene glycol (PEG) can alter polymer crystallinity, permeability, solubility and thereby results in faster degradation rate depending on the utilized ratios. Accordingly, copolymer compounds consisting of $P C L$ andPEG have attracted attention in the field of drug delivery research [7-10].

Besides, nanoparticle facilitates more tumor localization as the result of enhanced permeability and retention (EPR) effect [11]. Furthermore conjugating nanoparticles with specific ligands which their receptors are more expressed on cancer cells has been known as a promising approach for targeted 
delivery of drugs [12]. Folic acid (FA), a hydrophilic vitamin with a low molecular weight has been considered as one of these targeting ligand since it is well known that folate-receptors are over-expressed on the membrane of most of cancer cell lines $[13,14]$.

Incorporation of superparamagnetic iron oxide nanoparticles (SPION) into nanocarriers has been demonstrated to provide feasibility of detection and tracing via different technique such as Prussian blue staining, atomic absorption spectroscopy (AAS), inductively coupled plasma optical emission spectrometry (ICP-OES) and $\mathrm{T}_{2}$-weighted magnetic resonance imaging $\left(\mathrm{T}_{2} \mathrm{~W}-\mathrm{MRI}\right)$ [15-17].

In the current study, the SPION incorporated FA-PEG-PCL-PEG loaded with 5-FU was synthesized. To evaluate the role of folic acid as a targeting agent, Cellular uptake and cell viability assay was implemented in two different cell lines HT29 colon carcinoma and HUVEC human umbilical vein endothelial cells. Then, the cytotoxic effects of synthesized nanoparticles were investigated on HT29 based on expression of apoptosis related genes, induced cell death, reactive oxygen species production and colony formation assay

\section{Methods}

\section{Synthesis of Magnetite Nanoparticles}

Superparamagnetic iron oxide nanoparticles were synthesized according to the chemical coprecipitation method [18]. First, $\mathrm{FeCl}_{3} \cdot 6 \mathrm{H}_{2} \mathrm{O}(2.6 \mathrm{~g})$ and $\mathrm{FeCl}_{2} \cdot 4 \mathrm{H}_{2} \mathrm{O}(1 \mathrm{~g})$ were dissolved in deionized water and stirred at $70^{\circ} \mathrm{C}$ under a nitrogen atmosphere. Then, ammonia solution $25 \%(10 \mathrm{~mL})$ was added drop by drop. After stirring for $2 \mathrm{~h}$ (420 rpm), SPIONs were separated using external magnetic field and washed with water and ethanol, three and two times, respectively. At last, the nanoparticles were dried in vacuum at $45^{\circ} \mathrm{C}$ for $48 \mathrm{~h}$.

\section{Synthesis of poly ( $\varepsilon$-caprolactone) (PCL)}

$3 \mathrm{ml}$ of $\varepsilon$-caprolactone ( $27 \mathrm{mmol}$ ) was dissolved in $5 \mathrm{ml}$ of Dimethylformamide (DMF) in a three necked round bottom flask. Then, $5 \mu \mathrm{l}$ of ethylene glycol $(1 \mathrm{mmol})$ was added under a nitrogen atmosphere. The reaction temperature was gradually increased to $80^{\circ} \mathrm{C}$ followed by addition of stannous octoate [Sn $(\mathrm{Oct})_{2}$ ] and increasing temperature to $120^{\circ} \mathrm{C}$. After $24 \mathrm{~h}$, the polymer was precipitated in water at $0^{\circ} \mathrm{C}$ and then dried at $40^{\circ} \mathrm{C}$. In order to purify polymer, it was dissolved in DMF and precipitated in water. The product was obtained with $82 \%$ yield.

\section{Synthesis of adipoyl chloride -functionalized PCL}

$1 \mathrm{gr}$ of caprolactone $(0.2 \mathrm{mmol})$ was dissolved in DMF and $146 \mu \mathrm{l}(1 \mathrm{mmol})$ of adipoyl chloride and catalytic amount of triethylamine was added. The reaction was continued for $24 \mathrm{~h}$ at $80^{\circ} \mathrm{C}$. Then functionalized polymer was precipitated in water followed by drying in the vacuum oven at $40^{\circ} \mathrm{C}$. The purified product was obtained by dissolution of crude product in DMF and then precipitated in cold water. 


\section{Synthesis of PEG-PCL-PEG}

$1 \mathrm{gr}$ of functionalized PCL was dissolved in $10 \mathrm{ml}$ of dimethyl sulfoxide (DMSO) and afterward $206 \mathrm{mg} \mathrm{N}$, N'-Dicyclohexylcarbodiimide (DCC) and $122 \mathrm{mg}$ 4-Dimethylaminopyridine (DMAP) was gradually added to solution. After $1 \mathrm{~h}, 2 \mathrm{gr}$ of PEG was added and stirred at room temperature for $24 \mathrm{~h}$. PEG-PCL-PEG copolymer was precipitated in diethyl ether and then dried in vacuum oven at $40^{\circ} \mathrm{C}$. To have more purified product, dissolving in DMSO and precipitating in diethyl ether was repeated.

\section{Synthesis of folic acid functionalized PEG-PCL-PEG}

$220 \mathrm{mg}$ of folic acid, $103 \mathrm{mg}$ of DCC and $61 \mathrm{mg}$ of DMAP was dissolved in $10 \mathrm{ml}$ of DMSO and the reaction was continued for $4 \mathrm{~h}$ to activate acidic group of folic acid. Then $1 \mathrm{gr}$ of PEG-PCL-PEG copolymer was added and the reaction was continued overnight. After $24 \mathrm{~h}$, the product was precipitated in diethyl ether and dried at $40^{\circ} \mathrm{C}$. Dissolving in DMSO and precipitating in diethyl ether was repeated to acquire more purified product (Scheme 1).

\section{Synthesis of 5-FU loaded magnetite/PEG-PCL-PEG-Folic acid}

Preparation of the 5-FU loaded magnetite/PEG-PCL-PEG-Folic nanoparticles was performed by using W1/01/W2 double emulsion solvent evaporation method [19]. For preparation of inner aqueous solution (W1), $10 \mathrm{mg}$ of 5-FU drug was dissolved in $1.5 \mathrm{ml}$ of distilled water containing $10 \mathrm{mg}$ of Tween $60.30 \mathrm{mg}$ of magnetite nanoparticles was dispersed in $7 \mathrm{ml}$ of Dichloromethane (DCM) to prepare an organic phase using an ultrasonic probe. Then $50 \mathrm{mg}$ of the folic acid conjugated polymer (PEG-PCL-PEG-FA) and 200 $\mathrm{mg}$ of Span 60 were added to the oil phase (01). W2 aqueous solution was made of $100 \mathrm{mg}$ tween 60 dissolved in $8 \mathrm{ml}$ of distilled water and $8 \mathrm{ml}$ of glycerin. The inner aqueous solution (W1) was emulsified in the organic phase (01) by ultrasonication using the sonicator probe at an output of $50 \mathrm{~W}$ for $30 \mathrm{~s}$ in an ice-bath to obtain an W1/01 emulsion. This primary emulsion was emulsified in second aqueous solution (W2) by ultrasonication for $30 \mathrm{~s}(50 \mathrm{~W})$ in an ice-bath to obtain a W1/01/W2 double emulsion. The resulting double emulsion was diluted in $30 \mathrm{~mL}$ aqueous solution composed of $15 \mathrm{ml}$ distilled water and $15 \mathrm{ml}$ glycerin under mechanical stirring for a period of $3 \mathrm{~h}$ at room temperature, and the DCM was removed by solvent evaporation. The obtained magnetic nanoparticles were cleaned by repeating procedure of collecting and re-suspending in distilled water for two times and then were collected with a magnet. Finally, the resulting nanoparticles were dried by freeze-drying and stored at $4^{\circ} \mathrm{C}$. Blank nanoparticles were prepared in the same way, except that the inner aqueous solution was prepared with $1.5 \mathrm{ml}$ of distilled water and $10 \mathrm{mg}$ of tween 60 , but without 5 -FU drug.

\section{Proton nuclear magnetic resonance analysis}

In order to investigate synthesis procedure and characterize the structure of the synthesized products, the

${ }^{1} \mathrm{H}$ Nuclear Magnetic Resonance (NMR) analysis was performed on poly ( $\varepsilon$-caprolactone) (PCL), adipoyl chloride-functionalized PCL, PEG-PCL-PEG and folic acid functionalized PEG-PCL-PEGusing a Varian 
Inova, $500 \mathrm{MHz}$ spectrometer. Deuterated chloroform $\left(\mathrm{CDCl}_{3}\right)$ was used as solvent of samples to acquire ${ }^{1} \mathrm{H}$ NMR spectra.

\section{Characterization of size, zeta potential and morphology of nanoparticles}

Dynamic light scattering (DLS) analysis was used to characterize the distribution of the hydrodynamic size of blank and 5-FU loaded nanoparticles. The surface charge of nanoparticles was evaluated by Zeta sizer (Nanoflex, Germany).

The morphology of 5-FU loaded nanoparticles was investigated using a Transmission electron microscope (TEM, Zeiss LE0906, Germany). The samples were prepared on 400mesh carbon coated copper grid and imaged at accelerating voltage of $100 \mathrm{kV}$.

\section{Encapsulation efficiency and drug loading capacity}

To measure the drug loading capacity (DLC) and encapsulation efficiency (EE), $5 \mathrm{mg}$ of 5-FU- loaded NPs (5-FU-SPION-PEG-PCL-PEG-FA) was dissolved in acetone and its absorption was measured using a UVspectrophotometer (Ultraospec 3000, Pharmacia Biotech, USA) at a wavelength of $265 \mathrm{~nm}$ (characteristic absorption peak of $5-\mathrm{FU}$ ) followed by converting measured absorption to corresponding concentration according to calibration curve. The (DLC) and (EE) were determined according to equations 1 and 2:

$$
\begin{array}{ll}
\operatorname{DLC}(\%)=\frac{\text { weight of drug in nanoparticle }}{\text { nanoparticle weight }} & \text { Eq. } 1 \\
E E(\%)=\frac{\text { weight of drug in nanoparticle }}{\text { weight of drug in the feed }} & \text { Eq. } 2
\end{array}
$$

\section{In vitro drug release profiles}

Investigation of in vitro release profile of 5-FU from NPs (5-FU-SPION-PEG-PCL-PEG-FA) was carried out based on equilibrium dialysis bag diffusion method at $\mathrm{pH}=7.4$. First, $3 \mathrm{mg}$ of 5 -FU loaded NPs was suspended in Phosphate Buffer Saline (PBS) and transferred to a dialysis bag (MWCO 12,400 Da). The dialysis bag was fully immersed into a tube containing $10 \mathrm{~mL}$ PBS and stirred at the shaking speed of $100 \mathrm{rpm}$ at $37^{\circ} \mathrm{C}$. At predetermined time points, $1.5 \mathrm{ml}$ of media was sampled and replaced with an equal volume of PBS. The absorption of released 5-FU was measured using an UV-spectrophotometer at 265 $\mathrm{nm}$.

\section{Cell culture}

HT29 and HUVEC cells were respectively cultured in complete RPMI and DMEM/Ham's F-12 medium supplemented with $10 \% \mathrm{FBS}$, penicillin $(100 \mathrm{U} / \mathrm{mL})$ and streptomycin $(100 \mathrm{mg} / \mathrm{mL})$ under humidified incubator with $5 \%$ carbon dioxide at $37^{\circ} \mathrm{C}$. 


\section{MTT assay}

The cellular cytotoxicity of 5-FU and synthesized nanoparticles was investigated using MTT assay. In brief, HUVEC and HT-29 human colon cancer cells were cultured in a 96-well plate at a density of $7 \times 10^{3}$ cells per well. After $24 \mathrm{~h}$, the cells were treated with varying concentrations of 5-FU ranging from 0.6 to 80 $\mu \mathrm{M}$ and equivalent concentrations of blank and drug loaded NPs. After $48 \mathrm{~h}$ incubation, the cells were washed and treated with MTT $(5 \mathrm{mg} / \mathrm{ml})$. Plates were incubated at $37^{\circ} \mathrm{C}$ in the dark. After $4 \mathrm{~h}$, the medium containing MTT was removed followed by addition of $100 \mu \mathrm{l}$ of dimethyl sulfoxide (DMSO) and incubating for $15 \mathrm{~min}$ to solubilize formazan crystals. The absorbance was measured at $570 \mathrm{~nm}$ using a microplate reader (BioTek, Winooski, VT). Finally, cell viability was determined based on equation 3 :

$$
\text { cell viability }(\%)=\frac{\text { absorbance of treated cells }}{\text { absorbance of control cells }} \times 100 \quad \text { Eq. } 3
$$

To compare the cytotoxicity of 5-FU with 5-FU loaded nanoparticle on HT29 and HUVEC, the IC50 values of these agents was calculated regarding to cell viability curves and also a therapeutic index was defined as the ratio of IC50 of normal cell to IC50 of cancer cell [20].

\section{Cellular uptake of NPs}

\section{Prussian blue staining}

The cellular uptake of NPs was visually investigated using the Prussian blue staining assay. The HT 29 and HUVEC cell lines were seeded in 6-well plates. After 24h, both cell lines were incubated with amount of SPION-PEG-PCL-PEG-FA NPs which has capability of encapsulating IC10 of 5-FU against HT29 within $48 \mathrm{~h}$. After treatment time, the cells were washed with PBS for three times, then fixed with $4 \%$ paraformaldehyde solution for $20 \mathrm{~min}$ followed by staining with the Prussian blue solution ( $2 \%$ potassium ferrocyanid and $2 \%$ hydrochloric acid with 1:1 ratio) for 30 min. Subsequently, cells were washed with PBS, and imaged using an optical microscope at the magnification of 400X (Olympus CK2; Olympus Optical Co., Tokyo, Japan)

\section{Inductively coupled plasma optical emission spectrometry (ICP-OES)}

In order to quantitative evaluation of the cellular uptake of NPs, both cell lines were cultured in T-25 cell culture flasks at a density of $5 \times 10^{5}$ cells, treated in the same way as described before. After treatment, the cells were washed with PBS, trypsinized, collected and counted for quantification purposes. The cells were digested with $1 \mathrm{~mL}$ of concentrated $\mathrm{HNO}_{3}$ at $140^{\circ} \mathrm{C}$ for $2 \mathrm{~h}$. The samples were diluted to $5 \mathrm{~mL}$ with deionized water and the concentration of iron was measured using an ICP-OES assay (VISTA-PRO, Varian, Australia). Finally, the average iron content per cell was calculated. 


\section{In vitro anti-tumor effects of nanoparticles}

\section{Gene expression study using quantitative real-time PCR}

The HT29 cells were treated with 5-FU, 5-FU-SPION-PEG-PCL-PEG-FA, and SPION-PEG-PCL-PEG-FA for 48 $h$ as previously described. The cells were washed, trypsinized and collected. Then, total RNA of all samples was extracted using RNX-plus reagent (CinnaGen, Iran) according to the manufacturer's instructions. RNA concentration and purity were determined using a NanoDrop One Spectrophotometer (Thermo Scientific, USA). Afterward, $2 \mu \mathrm{g}$ of total RNA was reversely transcribed to synthesize cDNA using the cDNA Synthesis kit (Takara Bio Inc., Japan) according to its instructions. The obtained cDNA was employed in qRT-PCR to evaluate the expression of two member of BCL2 family genes: Bax and Bcl2. GAPDH was used as the house keeping gene. The reaction mixture was prepared according to PCR Master Mix Green (Ampliqon, Denmark) using real-time PCR StepOne plus (Applied Biosystems, USA) with a standard thermal profile. The protocol of reaction conditions was: initial denaturation at $95^{\circ} \mathrm{C}$ for $15 \mathrm{~min}$, followed by 40 cycles of denaturation at $95^{\circ} \mathrm{C}$ for $15 \mathrm{~s}$, and annealing/ extension at $60^{\circ} \mathrm{C}$ for $60 \mathrm{~s}$. The primer sequences were:

\begin{tabular}{|ll|}
\hline primer & Sequence \\
\hline GAPDH-f & CACATCGCTCAGACACCATG \\
\hline GAPDH-r & TGACGGTGCCATGGAATTTG \\
\hline Bax $-\mathrm{f}$ & AAGAAGCTGAGCGAGTGTCT \\
\hline Bax $-\mathrm{r}$ & GTTCTGATCAGTTCCGGCAC \\
\hline Bcl2-f & TCGCCCTGTGGATGACTGA \\
\hline Bcl2-r & CAGAGACAGCCAGGAGAAATCA \\
\hline
\end{tabular}

\section{Annexin V-FITC/PI double staining assay}

Flow cytometry analysis was carried out to examine the cell apoptosis induced by the 5-FU and NPs using the Annexin-V-FITC/Propidium iodide (PI) apoptosis detection kit according to the manufacturer's instructions (Mabtag). Briefly, after treatment of HT29 cells, the cells were washed with ice-cold PBS, trypsinized and suspended in the $1 \mathrm{X}$ binding buffer at a concentration of about $5 \times 10^{5}$ cells $/ \mathrm{mL}$. Thereafter, $5 \mu \mathrm{L}$ of FITC Annexin-V and $5 \mu \mathrm{L}$ of Propidium iodide (PI) were added to each sample and incubated for $15 \mathrm{~min}$ at room temperature under dark conditions then measured immediately to yield a FL-1 vs FL-2 dot plot in FACS (Becton Dickinson). The data were obtained by averaging of triple measurements.

\section{Measurement of ROS production}


Effects of aforementioned treatments on ROS formation was assessed by using 2',7'-dichlorofluorescein diacetate (DCFH-DA) which is the most common indicator of intracellular ROS [21]. DCFH-DA is a cell permeable dye which is first cleaved by intracellular esterase and then converted to its fluorescent derivative 2',7'-dichlorofluorescein (DCF), when oxidized by ROS. Briefly, cells were cultured into 24 -well plates and after $24 \mathrm{~h}$, they were treated as previously described. After $48 \mathrm{~h}$ incubation, the cells were washed followed by further incubation with DCFH-DA in dark condition at $37^{\circ} \mathrm{C}$ for $60 \mathrm{~min}$. Finally, cells were washed and DCF fluorescence was detected immediately using a plate reader at excitation wavelength of $485 \mathrm{~nm}$ and fluorescence emission at $530 \mathrm{~nm}$.

\section{Colony formation assay}

Assessment of the long-term cytotoxic effects of drug and NPs was implemented based on colony formation assay. The HT29 cell line at a density of $5 \times 10^{5}$ were cultured in T-25 cell culture flasks. After 24 $\mathrm{h}$ incubation, the cells were treated with 5-FU (at IC10 concentration), 5-FU-SPION-PEG-PCL-PEG-FA and SPION-PEG-PCL-PEG-FA (at the concentration that contains IC10 of 5-FU) for $48 \mathrm{~h}$. Then, the treated and control cells were washed with PBS and collected after trypsinization. Specified number of cells were seeded in $60 \mathrm{~mm}$ Petri dishes and incubated in RPMI with 10\% FBS for a period of 8 days. The cells were fixed using $4 \%$ Formaldehyde and finally stained with $0.5 \%$ Crystal violet. The colonies were counted using an optical microscope to determine the plating efficiency (PE) by equation 4 .

$$
P E(\%)=\frac{\text { number of the colonies }}{\text { number of cultured cells }} \quad \text { Eq. } 4
$$

The PE of treated groups were normalized to PE of control group to obtain corresponding survival fraction.

\section{Statistical analysis}

The results of all experiments were expressed as mean \pm standard deviation and analyzed using one-way analysis of variance (ANOVA) followed by Tukey's test using Graphpad prism 6. A p-value of 0.05 or lower was considered to be statistically significant.

\section{Results}

\section{Nuclear magnetic resonance analysis}

${ }^{1} \mathrm{H}$ NMR spectra of synthesized polymers were obtained and shown in Figure 1. The characteristic peaks of synthesized PCL were observed at about 4.1 (b), 1.6 (c) 1.4(d) and 2.3 ppm (e). Moreover, appearance of the three branched peaks at $4.2 \mathrm{ppm}$ was attributed to methylene and ethylene glycol groups (Figure $1 \mathrm{~A})$. As can be seen in spectrum B of this figure, a new peak was appeared at $3 \mathrm{ppm}$ as PCL was functionalized by adipoyl chloride which is attributed to methylene hydrogen in the vicinity of acyl group 
or carboxylic acid. Presence of intensified peak at $3.6 \mathrm{ppm}$ was related to methylene groups of polyethylene glycol in the spectrum of PEG-PCL-PEG (spectrum C). Functionalization of triblock copolymer by folic acid was confirmed by appearance of peaks at 4.4, 6.5 and 7.5 ppm (Figure 1D).

\section{Size, zeta potential, morphology and in vitro release of nanoparticles}

The hydrodynamic size of blank nanoparticles and drug loaded nanoparticles was measured using DLS which have mean diameter $37.2 \mathrm{~nm}$ and $85 \mathrm{~nm}$, respectively (Figure 2A\&B). TEM analysis of drug-loaded NPs confirmed that nanoparticles had a spherical shape with average particle size of about $50 \mathrm{~nm}$ (Figure 2C) that was slightly smaller than the hydrodynamic size measured by DLS which may be attributed to the attachment of $\mathrm{H}_{2} \mathrm{O}$ molecules on the NPs during the DLS analysis. The size and zeta potential of both NPs have been shown in Table 1. The DLC and EE was also shown in Table 1. The in vitro cumulative release profiles of 5-FU from 5-FU-SPION-PEG-PCL-PEG-FA at $37^{\circ} \mathrm{C}$ and $\mathrm{pH}=7.4$ have been shown in Figure 2D. As it is illustrated, a biphasic release pattern which was consist of an initial burst release, followed by a sustained drug release. The initial phase $20.05 \pm 0.33 \%$ of drug released within $8 \mathrm{~h}$. At later times, the rate of release tended to decrease in such a way that After $48 \mathrm{~h}$, the cumulative release was reached $26.25 \pm 0.78 \%$. A continuous release was also observed for 15 days and ultimately, $77.23 \pm 3.96 \%$ of cumulative release was attained.

\section{MTT assay}

To investigate the cytotoxic effects of 5-FU and synthesized NPs based on MTT assay, various concentrations of 5-FU and equivalent concentration of nanoparticles in the form of blank and drug loaded were added to HUVEC or HT-29 cells. As shown in Figure 3A\&B, the cytotoxicity of 5-FU, 5-FUloaded and blank nanoparticles against both of cell lines were concentration dependent. The inhibitory concentration (IC50) value of 5-FU, 5-FU-loaded and blank nanoparticles were 46.16 $\pm 4.7,5.1 \pm 0.88$ and $62.6 \pm 3.8 \mu \mathrm{M}$ for HT29 and $5.2 \pm 0.79,3.86 \pm 0.11$ and $71.4 \pm 1.8 \mu \mathrm{M}$ for HUVEC, respectively. These results demonstrated at equivalent concentration of 5-FU, treatment with 5-FU loaded nanoparticle leads to lower viability in comparison with free 5-FU. To further compare the cytotoxicity of 5-FU with 5-FU loaded nanoparticle on HT29 and HUVEC, the IC50 values of these agents was plotted (Figure 3C) and a therapeutic index was defined as the ratio of IC50 of normal cell to IC50 of cancer cell and illustrated in table 2.

IC10 concentration of 5-FU was calculated according to its cell viability curve against HT2 $(2.25 \mu \mathrm{M})$. Equivalent concentration of NPs which contains same amount of 5-FU was calculated using DLC and percentage of cumulative release at $48 \mathrm{~h}(21.9 \mu \mathrm{g} / \mathrm{mL})$. These concentrations were chosen as treatment dose to be employed for further experiments.

\section{Cellular uptake of NPs}

The uptake of nanoparticles in HUVEC and HT29 cell lines after $48 \mathrm{~h}$ with $21.9 \mu \mathrm{g} / \mathrm{ml}$ of NPs was confirmed by the Prussian blue staining (Figure 4). The quantitative cellular uptake was also assessed 
using ICP-OES method by measuring iron concentration. Based on this experiment, the average iron content was $2.96 \pm 0.27$ and $12.65 \pm 1.2 \mathrm{pg} /$ cell for HUVEC and HT29, respectively.

\section{In vitro anti-tumor effects of nanoparticles}

\section{Gene expression study using quantitative real-time PCR}

The mRNA expression of Bax and Bcl2 was investigated to compare the apoptotic effects of 5-FU, 5-FU loaded NPs and blank NPs. As depicted in Figure 5A, implementation of these treatments at equivalent 5FU concentration led to upregulation of Bax gene in 5-FU $(P<0.05)$ and 5 -FU loaded NPs groups $(P<0.001)$ while insignificant change in Bax gene was observed for blank NPs. The changes in level of $\mathrm{Bcl} 2$ gene found to insignificant. The ratio of $\mathrm{Bax} / \mathrm{Bcl} 2$, which is known as regulator of apoptosis [22], was calculated for different treatments (Figure 5B). Bax/Bcl2 ratio was remarkably higher in 5-FU and 5FU loaded NPs compared to control cells $(P<0.001)$. It was also found that 5 -FU loaded NPs results in further increase of Bax/Bcl2 ratio in comparison with $5-\mathrm{FU}(P<0.01)$.

\section{Annexin V-FITC/PI double staining assay}

In our study, the Annexin V-FITC/PI double fluorescent staining assay was used to determine the apoptosis and necrosis induced by treatments. As illustrated by flow cytometry analysis in Figure 5A \& B, 5-FU and 5-FU loaded NPs groups induced significant percentage of overall cell death (early apoptosis+ late apoptosis+ necrosis) in comparison to untreated group $(P<0.001)$. While, there was no significant differences between the control group and blank NPs $(P>0.05)$. The result of flow cytometry also revealed that 5-FU loaded NPs are superior to 5-FU regarding to overall cell death $(p<0.01)$.

\section{ROS generation}

According to DCF fluorescent intensity, 5-FU and 5-FU loaded NPs were identified as ROS generating agent $(\mathrm{P}<0.001)$. It was also corroborated that 5 -FU loaded NPs lead to produce higher amount of ROS as compared to $5-\mathrm{FU}(\mathrm{P}<0.01)$. Biocompatibility of blank NPs was illustrated in accordance to its insignificant DCF intensity $(P>0.05)$ (Figure 6A).

\section{Colony formation assay}

long term effects of $2.2 \mu \mathrm{M} 5-\mathrm{FU}, 21.9 \mu \mathrm{g} / \mathrm{mL}$ blank and $21.9 \mu \mathrm{g} / \mathrm{mL}$ drug loaded NPs (which contain IC10 of 5-FU) on HT29 cells was evaluated based on the colony formation assay. As illustrated in Figure $6 B$, the survival fraction (SF) of blank NPs had no significant difference with control cells $(P>0.05)$ which approved the safety of the blank NPs. The survival fraction of 5-FU alone and 5-FU loaded NPs was equal to $0.715 \pm 0.010$ and $0.627 \pm 0.051$, respectively. This result showed that anti proliferating effect of 5 -FU loaded NPs was significantly higher than that of 5-FU $(P<0.05)$.

\section{Discussion}


Although 5-FU is known as the mainstream in chemotherapy of broad range of cancers including breast and colorectal cancers, its short half-life in plasma, as well as wide systemic distribution, hinders it mostly to be reached to tumor sites. This drawback necessitate intermittent administration of high dose 5-FU which leads more severe side effects such as cardiotoxicity, vomiting, diarrhea, and severe anemia [23]. This issue can be addressed by incorporating 5-FU into polymeric nanoparticles through increasing blood circulation time and providing controlled drug release.

In current study, a sustained release has been provided by incorporating drug into synthesized polymer which is due to presence of PCL in copolymer structure. Because PCL is highly hydrophobic, it resists against water penetration that implies possessing very slow rate of degradation. However, this behavior of PCL is modified by copolymerization with PEG that results in accelerating degradation to some extent that is required for a drug nanocarrier. Slower release rate of 5-FU from PCL based NP in comparison with PLGA based NP has been reported which is known as manifestation of higher crystallinity nature [24, 25]. Furthermore, it has been demonstrated that hydrophobic/hydrophilic ratio has crucial role in stabilizing of formed micelle.it has been also reported the micelles formed by triblock copolymer are more advantageous over diblock formed micelles in terms of stability which is attributed to lower critical micelle concentration (CMC) of triblock copolymers [26]. PCL-PEG-PCL is a type of PCL/PEG based triblock which has been utilized as 5-FU nanocarrier [27]. A comprehensive evaluation on PCL/PEG based triblock, consisting PCL-PEG-PCL and PEG-PCL-PEG with different ratio of coplymerization, has demonstrated that CMC values of PEG-PCL-PEG type is about half of those measured for its identical PCL-PEG-PCL which indicates higher stability of PEG-PCL-PEG type [28]. So based on these evidences, the molecular weights of 2000 and $6000 \mathrm{gr} / \mathrm{mol}$ was considered for PEG and PCL respectively to synthesize PEG-PCL-PEG triblock. To take advantage of active targeting, folic acid was conjugated to the triblock copolymer. Since folic acid acts as a coenzyme in different cellular process such as DNA synthesis, repair and cell division, folate receptors are mainly overexpressed on the surface of most of cancer cells owing to their higher metabolism [29]. To examine whether the nanoparticle is actively targeted, cell viability using MTT assay was achieved on 2 different cell lines that differs in folate receptor expression level. In the case of treatment with 5-FU in the form of free drug, we observed HUVEC cells (the normal cell line) underwent severe cytotoxicity compared to HT29 regarding to their obtained IC50. This may attributed to high expression of multidrug resistance associated gene in cancer cells [30]. Nonetheless it was found that whereas IC50 of 5-FU loaded NPs against HT29 was drastically reduced compared to 5-FU alone, a mild decrease was seen in that of HUVEC. This indicates higher percent of cancer cells inhibition for a given level of normal cell cytotoxicity can be achieved by means of treatment with 5-FU loaded NPs which implies increased therapeutic index. This results is in accordance to what we expected due to folate receptor mediated endocytosis which is dominant in HT29 cells [31, 32] while HUVEC cells are known to express very low level of folate receptor [33].

The role of folic acid as a targeting ligand has been confirmed by San et al. They found that cellular uptake of Fol-Cur-NPs was greater than Cur-NPs in folate receptor expressing Y79 cells, whereas no significant difference in cellular uptake of Fol-Cur-NPs and Cur-NPs was found in folate receptor non- 
expressing A549 cells. The IC50 of Fol-Nut-Cur-NPs for Y79 cells was found to be 35 and 8.6 times lower compared to free drugs and uncojugated drug loaded NPs [34].

Antitumor efficacy of 5-FU and 5-FU loaded NPs was corroborated at utilized dose by different endpoints. This foundation could be ascribed to action of 5-FU. Several studies demonstrated that 5-FU induce apoptosis via generating ROS $[35,36]$. Further assessment indicated 5-FU loaded NPs possess more inhibitory efficiency than 5-FU on HT29 cells. This claim was approved according to higher ratio of $\mathrm{Bax} / \mathrm{Bcl} 2$, increased generation of ROS, less viable cell identified in Annexin V / PI staining and ultimately less clonogenicity of cells treated with 5-FU loaded NPs. This finding can be justified by considering their different cellular uptake pathways. It is well known that 5-FU as hydrophilic drug has a poor penetration into cell through diffusion and is highly prone to washed out while NPs could internalize into cell via endocytosis [23,37-40]. Endocytosis of NPs has been shown as an approach to bypass drug efflux pumps and subsequently reverse multidrug resistance [41-43]. In our study, folic acid conjugation was done to take advantage of more efficient type of endocytosis which is mediated by ligand- receptor interaction. Wang et al also have been reported An IC50 of $5.69 \mathrm{mg} / \mathrm{mL}$ for 5-FU loaded PLGA-1, 3diaminopropane-folic acid nanoparticles against HT29 cells that is considerably lower than IC50 of 14.17 and $22.91 \mathrm{mg} / \mathrm{mL}$ for 5-FU loaded PLGA and 5-FU alone respectively [31]. Another study that could be mentioned in case of enhancing effect of folic acid conjugation was conducted by Akinyelu et al [44]. They observed more significant cytotoxicity and apoptosis in MCF7 cells treated by 5-FU loaded Folatetagged chitosan-gold nanoparticles.

\section{Conclusion}

In current study folic acid conjugated PEG-PCL-PEG triblock copolymer were synthesized and subsequently loaded 5-FU and magnetite nanoparticle to constitute 5-FU-SPION-PEG-PCL-PEG-FA nanoparticles. This formalism was found to possess enhanced antitumor efficacy as compared to same concentration of free 5-FU. Therefore, we could conclude that it has the potential to be utilized as a targeted drug delivery system.

\section{List Of Abbreviation}

5-FU: 5- Fluorouracil

AAS: Atomic absorption spectroscopy

ANOVA: Analysis of variance

CMC: Critical micelle concentration

DCC: N, N'-Dicyclohexylcarbodiimide

DCF: 2',7'-dichlorofluorescein 
DCFH-DA: 2',7'-dichlorofluorescein diacetate

DCM: Dichloromethane

DLC: Drug loading capacity

DLS: Dynamic light scattering

DMAP: 4-Dimethylaminopyridine

DMF: Dimethylformamide

DMSO: dimethyl sulfoxide

DPD: dihydropyrimidine dehydrogenase

EE: Encapsulation efficiency

EPR: Enhanced and permeability retention

FA: Folic acid

FACS: Fluorescence Activated Cell Sorting

FBS: Fetal bovine serum

FDA: Food and drug administration

FITC: Fluorescein isothiocyanate

GAPDH: Glyceraldehyde 3-phosphate dehydrogenase

IC50: half maximal inhibitory concentration

ICP-OES: Inductively coupled plasma optical emission spectrometry

MRI: Magnetic resonance imaging

MTT: 3-(4,5-dimethylthiazol-2-yl)-2,5-diphenyltetrazolium bromide

NMR: Nuclear Magnetic Resonance

NPs: Nanoparticles

PBS: Phosphate buffer saline

PCL: Poly - $\varepsilon$-caprolactone 
PE: Plating efficiency

PEG: Poly-ethylene glycol

Pl: propidium lodide

qRT-PCR: quantitative real time polymerase chain reaction

ROS: Reactive oxygen species

rpm: revolution per minute

Sn $(\mathrm{Oct})_{2}:$ Stannous octoate

SPION: Superparamagnetic iron oxide nanoparticles

TEM: Transmission electron microscope

\section{Declarations}

Ethics approval and consent to participate

Not applicable

\section{Consent for publication}

Not applicable

\section{Availability of data and materials:}

All data generated and / or analyzed during the present study are available from the corresponding author on reasonable request.

\section{Competing interests:}

The authors declare that they have no competing interests

\section{Funding:}

This research was funded by Iran University of Medical Sciences (IUMS) (grant No. 13891).

\section{Author's contributions}

S Khoei and S Khoee were responsible of conception and design of study. P.S. Mirzaghavami and S Shirvalilou were responsible of laboratory data acquisition and data analysis. S Khoei and P S 
Mirzaghavami were responsible of article drafting and critical revision. All authors approved the final version of the manuscript.

\section{References}

1. Siegel, R.L., et al., Colorectal cancer statistics, 2017. CA: a cancer journal for clinicians, 2017. 67(3): p. 177-193.

2. Longley, D.B., D.P. Harkin, and P.G. Johnston, 5-fluorouracil: mechanisms of action and clinical strategies. Nature reviews cancer, 2003. 3(5): p. 330-338.

3. Bodratti, A.M. and P. Alexandridis, Amphiphilic block copolymers in drug delivery: Advances in formulation structure and performance. Expert opinion on drug delivery, 2018. 15(11): p. 1085-1104.

4. Vlassi, E., A. Papagiannopoulos, and S. Pispas, Amphiphilic poly (2-oxazoline) copolymers as selfassembled carriers for drug delivery applications. European Polymer Journal, 2017. 88: p. 516-523.

5. Ferrari, R., et al., Synthesis of surfactant free PCL-PEG brushed nanoparticles with tunable degradation kinetics. International journal of pharmaceutics, 2013. 453(2): p. 551-559.

6. Almeida, B.C., P. Figueiredo, and A.T. Carvalho, PCL enzymatic hydrolysis: a mechanistic study. arXiv preprint arXiv:1903.11597, 2019.

7. Nguyen, T.H.A. and V.C. Nguyen, Formation of nanoparticles in aqueous solution from poly ( $\varepsilon$ caprolactone)-poly (ethylene glycol)-poly ( $\varepsilon$-caprolactone). Advances in Natural Sciences: Nanoscience and Nanotechnology, 2010. 1(2): p. 025012.

8. Wang, Y., et al., Pharmacokinetics and disposition of nanomedicine using biodegradable PEG/PCL polymers as drug carriers. Current drug metabolism, 2012. 13(4): p. 338-353.

9. Wang, Q., et al., Targeted delivery of low-dose dexamethasone using PCL-PEG micelles for effective treatment of rheumatoid arthritis. Journal of Controlled Release, 2016. 230: p. 64-72.

10. Wang, H., et al., A facile strategy for fabricating PCL/PEG block copolymer with excellent enzymatic degradation. Polymer Degradation and Stability, 2017. 140: p. 64-73.

11. Stylianopoulos, T., EPR-effect: utilizing size-dependent nanoparticle delivery to solid tumors. Therapeutic delivery, 2013. 4(4): p. 421-423.

12. Kumari, S. and A.K. Kondapi, Lactoferrin nanoparticle mediated targeted delivery of 5-fluorouracil for enhanced therapeutic efficacy. International journal of biological macromolecules, 2017. 95: p. 232-237.

13. Song, Y., et al., Fluorescent carbon nanodots conjugated with folic acid for distinguishing folatereceptor-positive cancer cells from normal cells. Journal of Materials Chemistry, 2012. 22(25): p. 12568- 
12573.

14. Kularatne, S.A. and P.S. Low, Targeting of nanoparticles: folate receptor, in Cancer Nanotechnology. 2010, Springer. p. 249-265.

15. Jin, R., et al., Superparamagnetic iron oxide nanoparticles for MR imaging and therapy: design considerations and clinical applications. Current opinion in pharmacology, 2014. 18: p. 18-27.

16. Minaei, S.E., S. Khoei, and S. Khoee, Tri-block copolymer nanoparticles modified with folic acid for temozolomide delivery in glioblastoma. The international journal of biochemistry \& cell biology, 2019. 108: p. $72-83$.

17. Kargar, S., et al., Evaluation of the combined effect of NIR laser and ionizing radiation on cellular damages induced by IUdR-loaded PLGA-coated Nano-graphene oxide. Photodiagnosis and photodynamic therapy, 2018. 21: p. 91-97.

18. Shirvalilou, S., et al., Development of a magnetic nano-graphene oxide carrier for improved gliomatargeted drug delivery and imaging: In vitro and in vivo evaluations. Chemico-biological interactions, 2018. 295: p. 97-108.

19. Ashjari, M., S. Khoee, and A.R. Mahdavian, Controlling the morphology and surface property of magnetic/cisplatin-loaded nanocapsules via W/O/W double emulsion method. Colloids and Surfaces A: Physicochemical and Engineering Aspects, 2012. 408: p. 87-96.

20. Deepa, P.R., et al., Therapeutic and toxicologic evaluation of anti-lipogenic agents in cancer cells compared with non-neoplastic cells. Basic \& clinical pharmacology \& toxicology, 2012. 110(6): p. 494503.

21. Afri, M., A.A. Frimer, and Y. Cohen, Active oxygen chemistry within the liposomal bilayer: part IV: locating 2', 7'-dichlorofluorescein (DCF), 2', 7'-dichlorodihydrofluorescein (DCFH) and 2', 7'dichlorodihydrofluorescein diacetate (DCFH-DA) in the lipid bilayer. Chemistry and physics of lipids, 2004. 131(1): p. 123-133.

22. Agarwal, M.K., et al., Tocotrienol-rich fraction of palm oil activates $p 53$, modulates Bax/Bcl2 ratio and induces apoptosis independent of cell cycle association. Cell cycle, 2004. 3(2): p. 200-199.

23. de Mattos, A.C., et al., Polymeric nanoparticles for oral delivery of 5-fluorouracil: Formulation optimization, cytotoxicity assay and pre-clinical pharmacokinetics study. European Journal of Pharmaceutical Sciences, 2016. 84: p. 83-91.

24. Wang, S., et al., Degradation and 5-fluorouracil release behavior in vitro of polycaprolactone/poly (ethylene oxide)/polylactide tri-component copolymert 1. Polymers for Advanced Technologies, 2001. 12(3-4): p. 253-258. 
25. Ashour, A.E., et al., Physical PEGylation Enhances The Cytotoxicity Of 5-Fluorouracil-Loaded PLGA And PCL Nanoparticles. International Journal of Nanomedicine, 2019. 14: p. 9259.

26. Lin, W.J., C.L. Wang, and L.W. Juang, Characterization and comparison of diblock and triblock amphiphilic copolymers of poly (ס-valerolactone). Journal of applied polymer science, 2006. 100(3): p. 1836-1841.

27. Asadi, N., et al., Synthesis, characterization and in vitro evaluation of magnetic nanoparticles modified with PCL-PEG-PCL for controlled delivery of 5FU. Artificial cells, nanomedicine, and biotechnology, 2018. 46(sup1): p. 938-945.

28. Zamani, S. and S. Khoee, Preparation of core-shell chitosan/PCL-PEG triblock copolymer nanoparticles with $A B A$ and $B A B$ morphologies: Effect of intraparticle interactions on physicochemical properties. Polymer, 2012. 53(25): p. 5723-5736.

29. Zhao, X., H. Li, and R.J. Lee, Targeted drug delivery via folate receptors. Expert opinion on drug delivery, 2008. 5(3): p. 309-319.

30. Plasencia, C., et al., Expression analysis of genes involved in oxaliplatin response and development of oxaliplatin-resistant HT29 colon cancer cells. International journal of oncology, 2006. 29(1): p. 225-235.

31. Wang, Y., et al., Targeted delivery of 5-fluorouracil to HT-29 cells using high efficient folic acidconjugated nanoparticles. Drug delivery, 2015. 22(2): p. 191-198.

32. Handali, S., et al., A novel 5-Fluorouracil targeted delivery to colon cancer using folic acid conjugated liposomes. Biomedicine \& Pharmacotherapy, 2018. 108: p. 1259-1273.

33. Qiu, L., C. Dong, and X. Kan, Lymphoma-targeted treatment using a folic acid-decorated vincristineloaded drug delivery system. Drug design, development and therapy, 2018. 12: p. 863.

34. Das, M. and S.K. Sahoo, Folate decorated dual drug loaded nanoparticle: role of curcumin in enhancing therapeutic potential of nutlin-3a by reversing multidrug resistance. PloS one, 2012. 7(3).

35. Focaccetti, C., et al., Effects of 5-fluorouracil on morphology, cell cycle, proliferation, apoptosis, autophagy and ROS production in endothelial cells and cardiomyocytes. PloS one, 2015. 10(2).

36. Lamberti, M., et al., 5-Fluorouracil induces apoptosis in rat cardiocytes through intracellular oxidative stress. Journal of Experimental \& Clinical Cancer Research, 2012. 31(1): p. 60.

37. Handali, S., et al., Co-delivery of 5-fluorouracil and oxaliplatin in novel poly (3-hydroxybutyrate-co-3hydroxyvalerate acid)/poly (lactic-co-glycolic acid) nanoparticles for colon cancer therapy. International journal of biological macromolecules, 2019. 124: p. 1299-1311. 
38. Sharma, A., et al., Stealth recombinant human serum albumin nanoparticles conjugating 5-fluorouracil augmented drug delivery and cytotoxicity in human colon cancer, HT-29 cells. Colloids and Surfaces B: Biointerfaces, 2017. 155: p. 200-208.

39. Wang, T., et al., Hyaluronic acid-coated chitosan nanoparticles induce ROS-mediated tumor cell apoptosis and enhance antitumor efficiency by targeted drug delivery via CD44. Journal of nanobiotechnology, 2017. 15(1): p. 7.

40. Esmaelbeygi, E., et al., Role of iron oxide core of polymeric nanoparticles in the thermosensitivity of colon cancer cell line HT-29. International Journal of Hyperthermia, 2015. 31(5): p. 489-497.

41. Markman, J.L., et al., Nanomedicine therapeutic approaches to overcome cancer drug resistance. Advanced drug delivery reviews, 2013. 65(13-14): p. 1866-1879.

42. Yuan, Y., et al., Nanoparticle delivery of anticancer drugs overcomes multidrug resistance in breast cancer. Drug Delivery, 2016. 23(9): p. 3350-3357.

43. Zhou, M., et al., Overcoming chemotherapy resistance via simultaneous drug-efflux circumvention and mitochondrial targeting. Acta Pharmaceutica Sinica B, 2019. 9(3): p. 615-625.

44. Akinyelu, J. and M. Singh, Folate-tagged chitosan-functionalized gold nanoparticles for enhanced delivery of 5-fluorouracil to cancer cells. Applied Nanoscience, 2019. 9(1): p. 7-17.

\section{Tables}

Table 1. The characterization of nanoparticles

\begin{tabular}{|lllll|}
\hline Nanoparticles & size & Zeta potential & DLC (\%) & EE (\%) \\
& & & & \\
SPION-PEG-PCL-PEG-FA & 37.2 & -27 & - & - \\
\hline 5-FU-SPION-PEG-PCL-PEG-FA & 85 & -20.1 & 5 & 56 \\
\hline
\end{tabular}

Table 2. Therapeutic index of 5-FU and 5-FU loaded NPs

\begin{tabular}{|lll|}
\hline treatment & $5-\mathrm{FU}$ & $\mathrm{NP}(5-\mathrm{FU})$ \\
\hline Therapeutic index & 0.113 & 0.756 \\
\hline
\end{tabular}




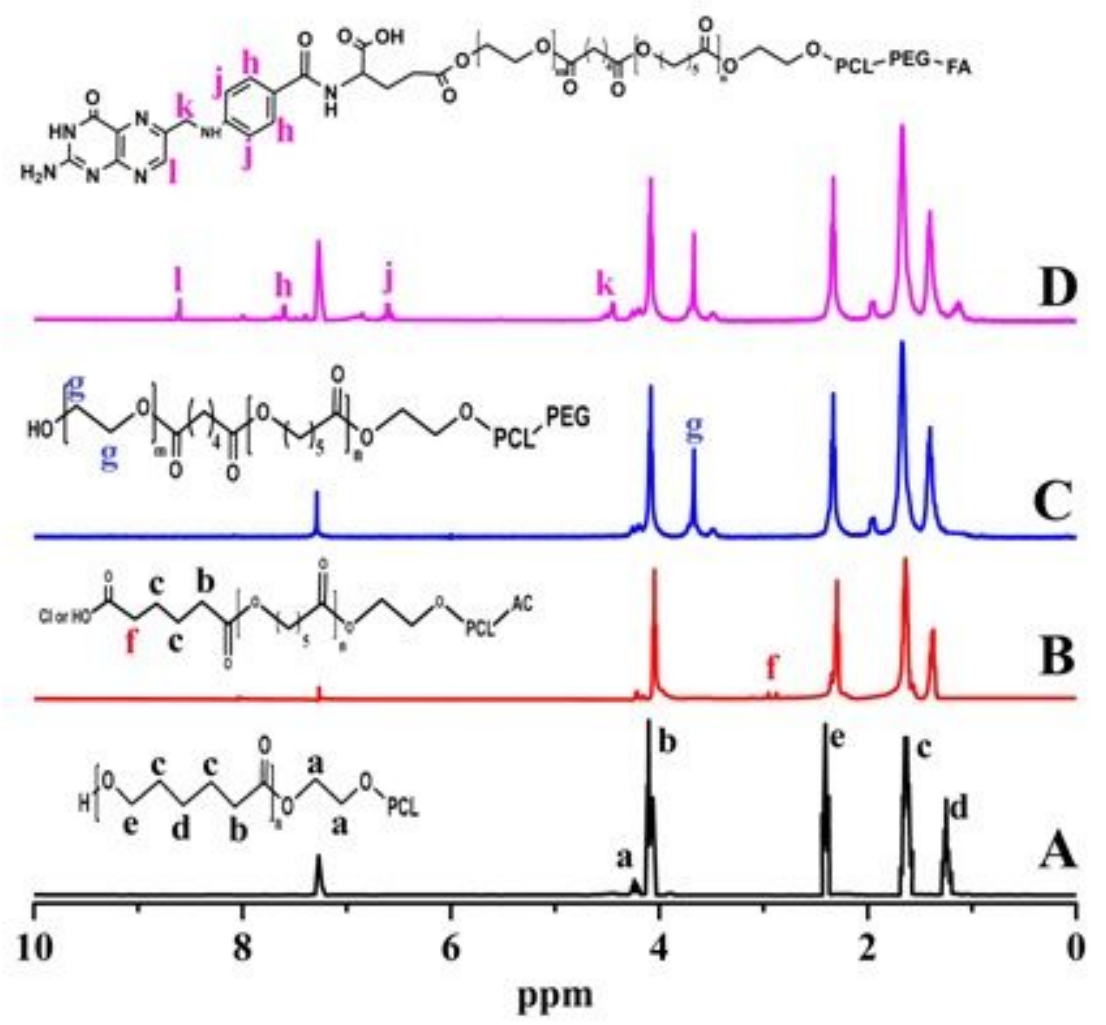

Figure 1

$1 \mathrm{H}$ NMR Spectra of synthesized polymers: on poly ( $\varepsilon$-caprolactone) $(\mathrm{PCL})(\mathrm{A})$, adypoil chloride functionalized PCL(B), PEG-PCL-PEG (C) and folic acid functionalized PEG-PCL-PEG (D)

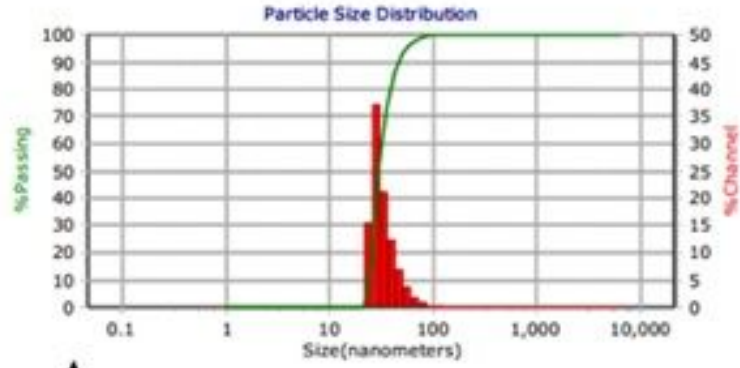

A

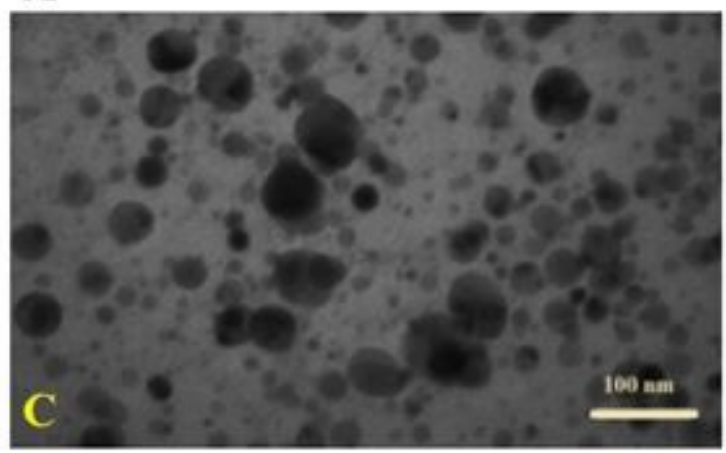

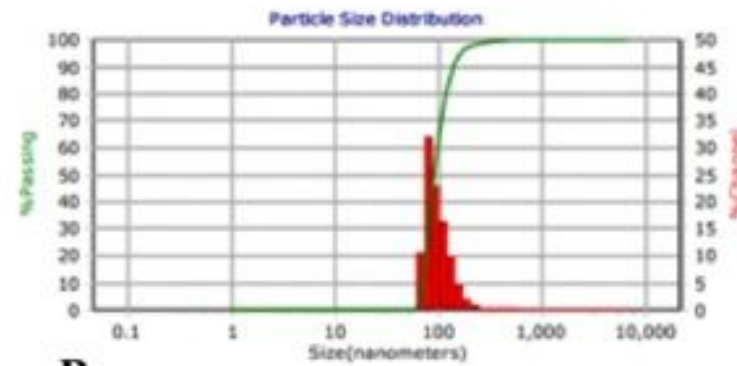

B

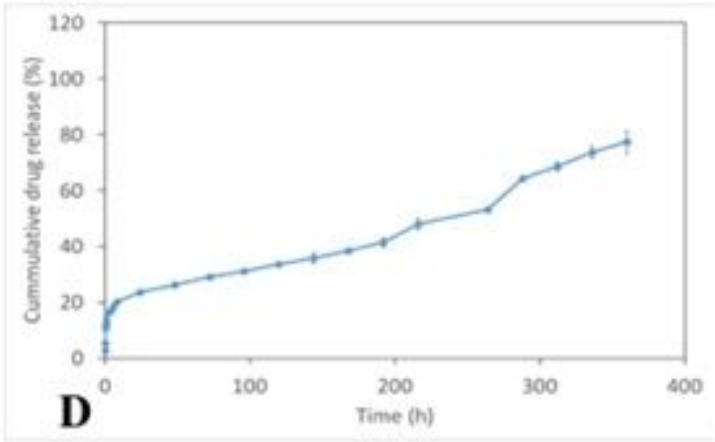

Figure 2 
Characterization of nanoparticles particle size distribution measurements using DLS: A) SPION-PEG-PCLPEG-FA, B) 5-FU-SPION-PEG-PCL-PEG-FA, C) TEM image of 5-FU-SPION-PEG-PCL-PEG-FA and D)in vitro 5$\mathrm{FU}$ release in $\mathrm{PBS}(\mathrm{pH}=7.4)$ at $37^{\circ} \mathrm{C}$.
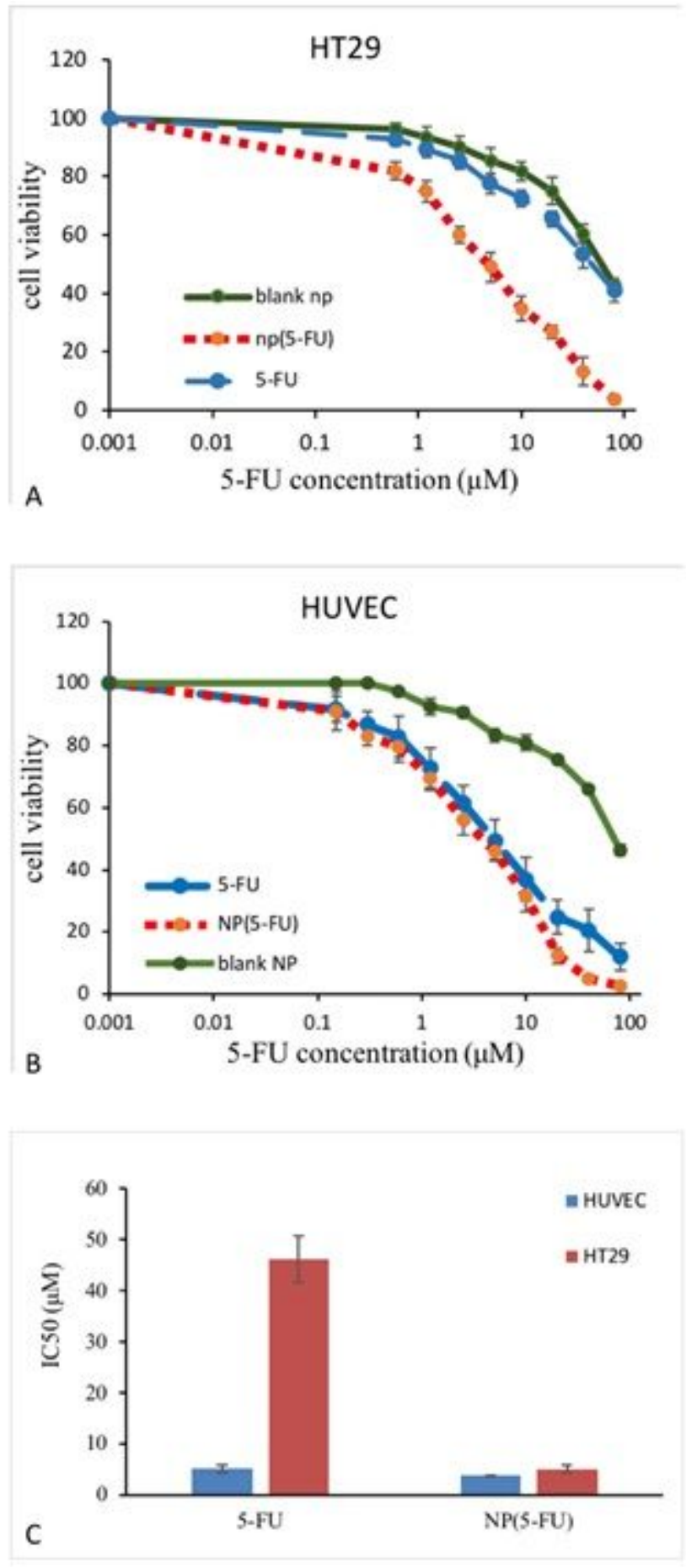

\section{Figure 3}

In vitro cell viability assessment using MTT assay after $48 \mathrm{~h}$ incubation of HT29 (A) and HUVEC (B) cells with blank NPs, 5-FU and 5-FU loaded NPs. (C) Calculated IC50 of 5-FU and 5-FU loaded NPs against HUVEC and HT29 cells based MTT cell viability curves. 

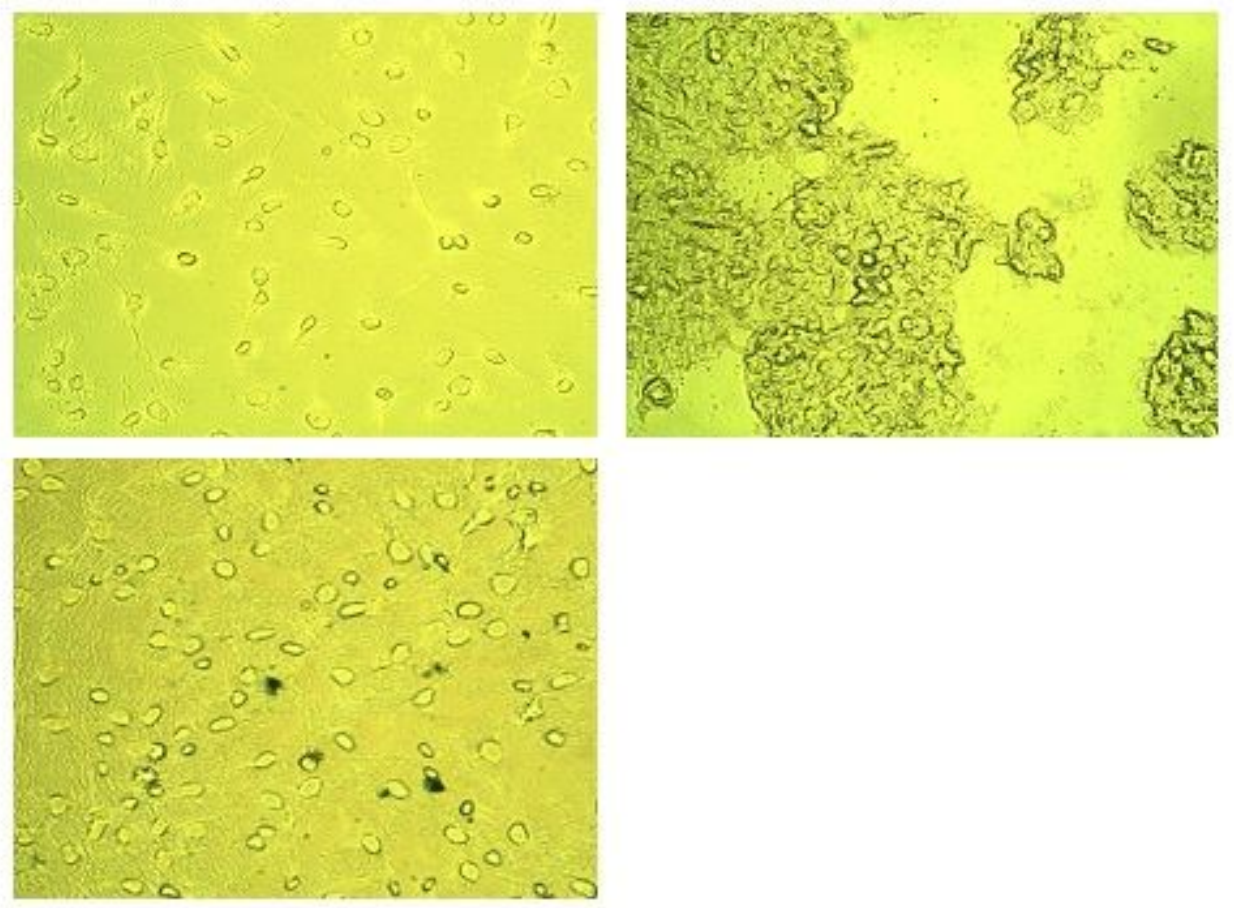

Figure 4

Uptake of NPs by HUVEC and HT29 cells after $48 \mathrm{~h}$ incubation 


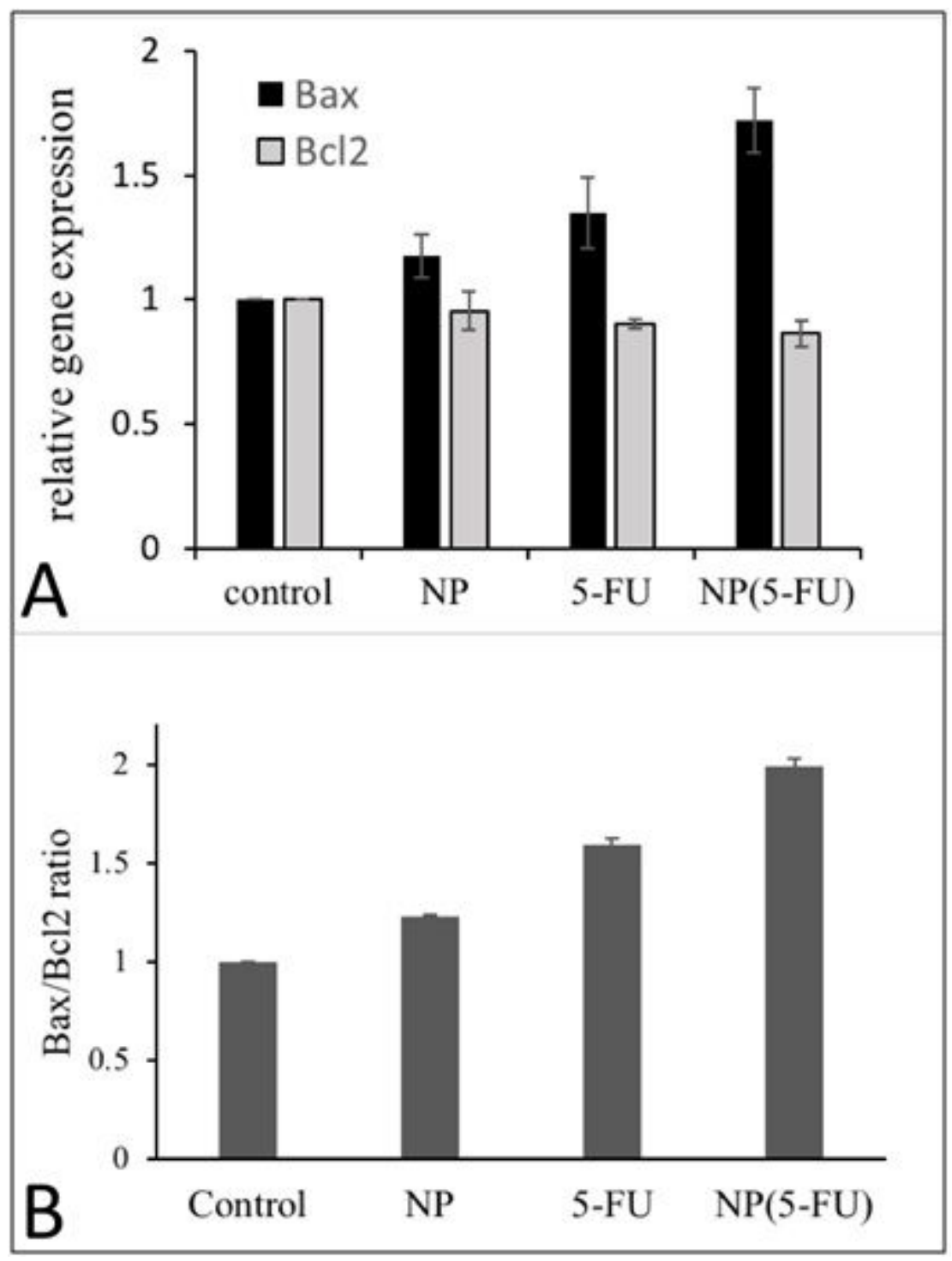

Figure 5

A) Quantitative real time PCR analysis of expression of Bax and Bcl2 genes in HT29 cells as the result of treating with blank NPs, 5-FU, 5-FU loaded NPs. B) Bax/Bcl2 ratio obtained for aforementioned treatments. 

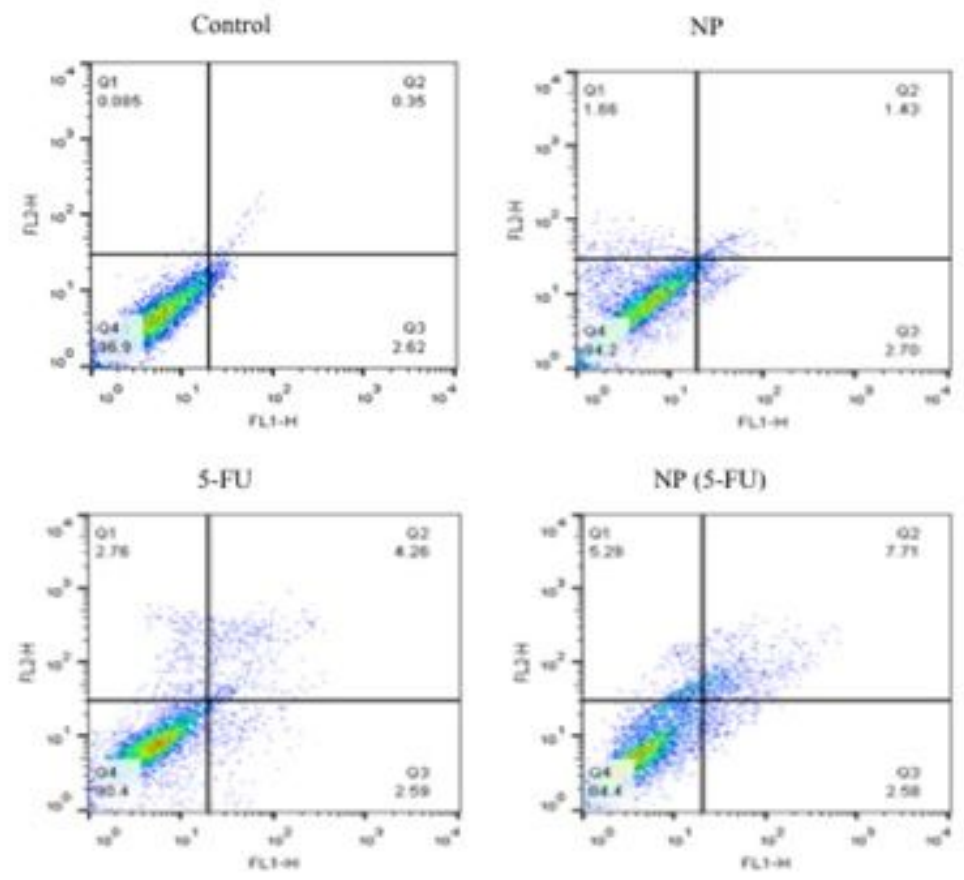

A

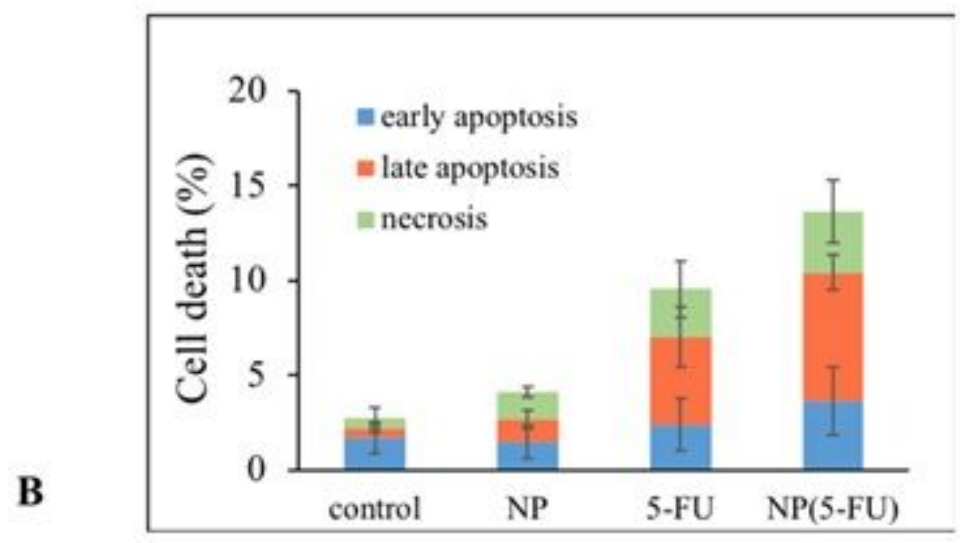

\section{Figure 6}

A) The Annexin V/PI staining assay for cell death detection in HT29 cells. B) the mean percentage of apoptosis and necrosis of HT29 cells after $48 \mathrm{~h}$ treatment by blank NPs, 5-FU, 5-FU loaded NPs. 

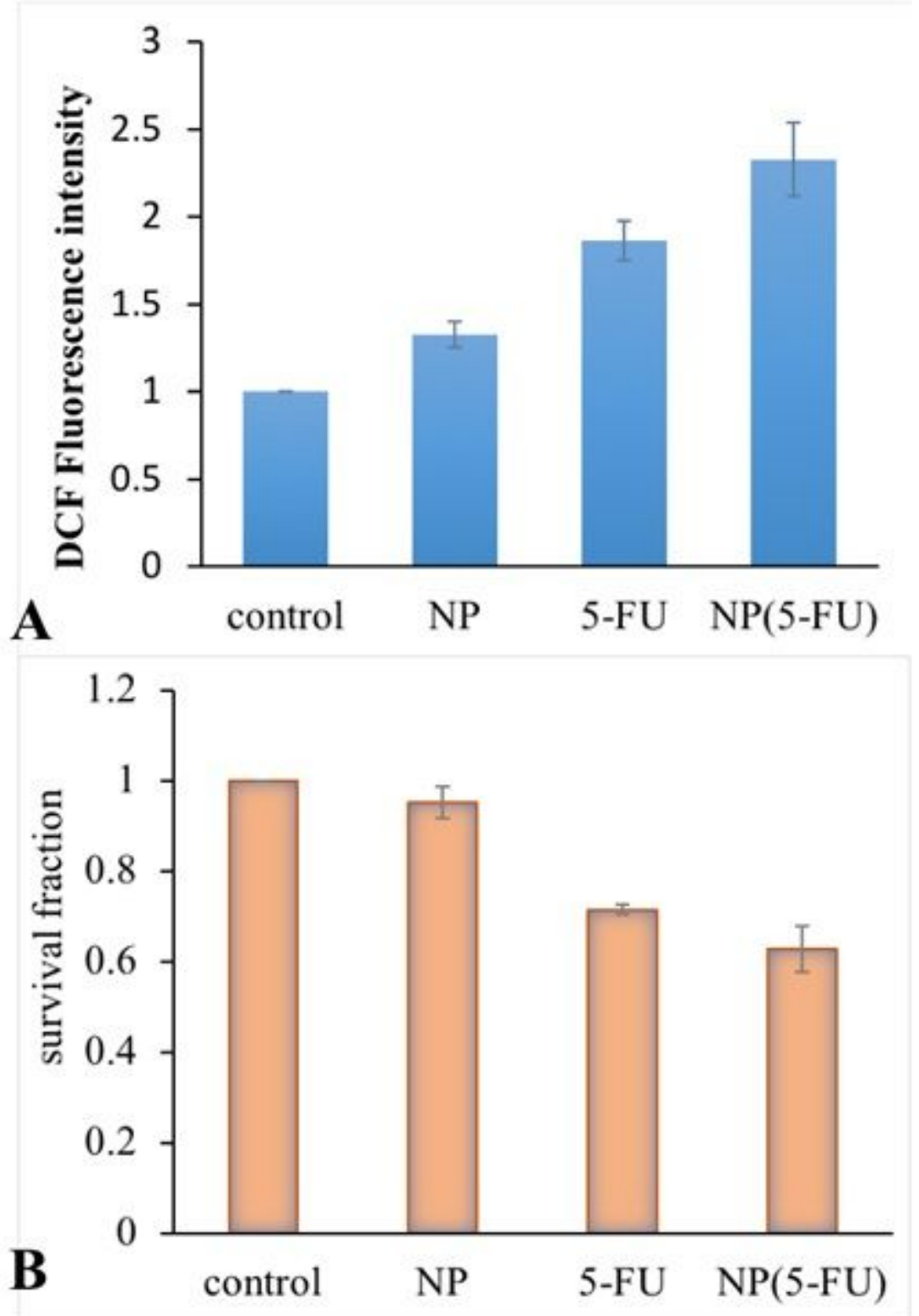

Figure 7

A) Effects of blank NPs, 5-Fu and 5-FU loaded NPs on DCF fluorescence intensity and B) survival fraction of HT29 cells after $48 \mathrm{~h}$ of incubation

\section{Supplementary Files}

This is a list of supplementary files associated with this preprint. Click to download.

- Scheme1.jpg

- Scheme1.jpg 